\title{
Suggestions for increasing knowledge of the circulation of the North Sea waters to serve pollutant-drift studies
}

\author{
James N. CARruthers \\ British National Institute of Oceanography, Wormley, U.K.
}

KURZFASSUNG: Vorschläge zur Erweiterung der Kenntnisse über die Wasserzirkulation der Nordsee als Stütze für die Durchführung von Verunreinigungsdrift-Studien. Genaue Kenntnisse über die Wasserzirkulation in der Nordsee sind erforderlich, um den verantwortlichen Instanzen sinnvolle Vorschläge über Art und Ausmaß des Einbringens von Abwasserinhaltsstoffen unterbreiten zu können. Am Beispiel der Einleitung häuslicher Abwässer in küstennahe Nordseegebiete wird die Bedeutung der Wasserzirkulation erläutert. Eine Reihe praktischer Vorschläge für die Durchführung einfacher, aber dringend erwünschter einschlägiger Forschungsprojekte wird erörtert.

\section{INTRODUCTION}

It is an interesting exercise to look ahead to the end of a symposium devoted to such an important topic as this is, and to consider hopefully some of the things which one would personally most like to have emerged from it. I shall myself listen with keen interest to all that is promised, but $I$ shall be best pleased if we hear of some practical ameliorative measures which can be taken to counter pollutions of the marine environment which are likely always to be with us. Taking one such only - the discharge of municipal sewage effluents into coastal waters - I shall make suggestions for increasing our knowledge of the North Sea currents to the end that the best possible advice can be given towards the achievement of the most effective dispersal. Though my restricted theme will look small against ideas which others may present to deal with great catastrophic pollutions happily of rare occurrence, some progress will undoubtedly be made if various contributors make practical suggestions for combating specific pollutions threatened or existing. Though my own interest is largely restricted to coastal waters, I shall not so restrict my suggestions for improving knowledge of the North Sea circulation - because need may arise to take account of pollution in the open reaches of that sea as well.

\section{SUGGESTIONS}

At the outset of my address to this distinguished assembly, I should remark that my personal concern with questions of pollution, in so far as the North Sea is 
concerned, has been limited to consultations regarding sewage discharges made into it, and, because we have been asked to advise where outfalls could best be located to achieve good dispersal, I propose to consider what could certainly be done to increase that knowledge of the movements of the North Sea's waters which we must have before we can put advice on a sounder basis than is at present possible.

I could easily give you a long address based upon past knowledge of the currents of the North Sea because they were my personal study for many years, but I am happy to leave a present-day account to my friends from Lowestoft who can add so much information gained since the time that my own investigations ceased. With only meagre citation from the past, I would like to suggest some things that could profitably be done in the future with the certainty of adding very much of real value to what we know at present. Any body of knowledge which will suffice must, of course, include bad weather conditions. That being so, I took pains many years ago to produce a current-measuring instrument which was robust enough to tolerate more or less all weather conditions. This, installed aboard a dozen and more lightships was in continuous use for many years, and one result of its use was the production on Admiralty Chart 5057 of a portrayal of residual currents in the southern North Sea which takes account of their dependence upon wind conditions. The chart in question has been reproduced in the Special Issue Number 1 to Volume 1 of the Hydrographic Newsletter of the Netherlands Hydrographic Department (1965). I mention this chart because I had always hoped one day to become able to extend the presentation further and further northwards over the North Sea. Unfortunately, the absence of light vessels which alone could then provide observing platforms for contin u ous all-weather current measurements put the hope out of court. I do indeed hold most strongly that the programme of continuous allweather current-measuring should be re-instituted on all existing lightships. The cost would be modest in comparison with that of certain other expensive, irregular, and less-fruitful activities, and, in any case, the Netherlands authorities still keep the programme in being aboard their lightships. A moot question is: what could be done over the wider and deeper reaches of the North Sea to enable us to keep track of the upper currents there where lightships do not avail? If dependence upon moored recording current-meters of various modern kinds be contemplated will space and time coverage ever be adequate, will seriously expensive losses ever be avoided, will ship attendance costs not be exorbitant, and shall we be able to get the records we want, or shall we have to be content with what the moored meters can provide - if the two things are not the same? Will the current-meters dictate to us so to speak rather than we to them? By the last remark I mean just this: most kinds of moored recording meters will always have to work at a "safe" depth to escape the nearsurface wave conditions which could well put them out of commission, and the information from that depth might not be what we want. Then too, in the modest depths of the North Sea at its deepest, the big variations in tidal stream strength will militate to produce records not relating to a single level. The difficulties seem serious to me, but our Lowestoft friends will doubtless tell us how they have operated and how they have fared.

My own thinking in the years just before World War II, was that the only 
way to hope to achieve an adequate time and space coverage of the upper layer currents over the wide reaches of the North Sea, would be by the method of Route Indicating Drift Bottles if ever this could be sufficiently developed. In those days I did preliminary experiments with drift bottle systems which would float for a time and would then drop a questionnaire-containing bottle to the bottom there to remain until recovered by trawl or other ground fishing gear. The idea promised very well, but I could not then be satisfied with stated recovery positions given by skippers. The situation is vastly different now that so many fishing vessels have Decca. My floatation times were not regular in those days, but enough was done to demonstrate with certainty that systems riding a fathom deep travelled downwind. Under prevailing winds from N.E., S.E., S.W. and N.W., the systems travelled, respectively S.W., N.W., N.E. and S.E. in regions under the sway of strong tidal streams. There seems no reason why Route-Indicating Bottle systems could not be made in such a simple form that cartons of them could be put aboard vessels plying fixed routes with arrangements made that a junior officer (for a modest fee) would put them out at fixed positions along each regular crossing. If made simple enough, all he would have to do would be to log identity numbers and positions of settingout. Required would be of course a cheap and reliable perishing link which would drop the questionnaire bottle after a travel of known time duration. This should not be very difficult to provide, and I personally think that it could one day be possible to have liberations of such bottle systems made from passenger vessels crossing the North Sea regularly on routes enough to provide a good space coverage. Of course, the method would be restricted (initially at least) to regions where bottom fishing is prosecuted.

One can of course think of other ways of observing the currents over the middle and northern reaches of the North Sea on special occasions for special purposes - as by photographing the positions of large recognisable floats at intervals from aircraft - but $I$ have in mind methods which could always be kept in being. One extremely useful thing to do would be to repeat what was once done in 1906 when a wreck lightship was hired and towed out to be anchored on the Dogger Bank for use as a scientific observing platform. Such a green-painted unengined vessel conventionally lighted would presumably give no offence to mariners, would be perfectly safe if moored by the proper experts, would serve for good spells of allweather currents observing, and could be moved from place to place at, say, monthly intervals. Though the idea may sound preposterous in these days of high wages and high costs of other kinds, the possession of such a facility could not fail to bring great benefits to the gathering of information on currents. Sometimes interest might attach to bottom water movements as at the outlet of a pipe emitting effluents a mile or two offshore. To measure the bottom current hour after hour for all states of tide is a simple matter indeed with no dependence at all upon weather within the seakeeping capacity of the unanchored observing vessel. The device which serves for depths up to 60 fathoms is the simple current-measuring bottle described in the leaflet which I have placed on the table. If these bottles were used regularly from lightships and hourly as often as possible from research vessels over a tidal period, the cost would be very reasonable, and a good groundwork could soon be laid to- 
wards the production of an atlas of bottom currents of the North Sea. This would be very useful not only to the engineers drilling for oil and gas, but also in connection with certain aspects of open sea pollution - as for instance when masses of unwanted explosives are dumped on the seabed, and when effluent discharge pipes have to be laid to reach well offshore. We keep in mind of course the distinction between observations on currents always kept in train, and those done on special occasions for special purposes. As regards the former, the best use possible should be made of the stilted oil rigs now in position. I am aware that some current measurements are being made from them already, but it would be possible without using expensive meters which need some degree of nursing and have weather limitations, to install a system advocated twenty years ago in the pages of the Journal du Conseil of the I.C.E.S. If a Vertical Log were suspended from the end of a long spar set out from the rig, and if its revolutions were made to drop balls from a large hopper mounted above a spinning bollard (well back on deck and orientated by the current) in the manner described when a "marriage" of the Vertical Log and the Drift Indicator was then advocated, one would have a sure means of achieving a very valuable northwards extension of those continuous observations the resumption of which from all the lightships of the southern North Sea is strongly urged. Moreover, there would be no need to "read" the instrument frequently; once a day or once a week would suffice.

With anemometers installed on the rigs - preferably of the totalising type advocated thirty years ago, one would quickly build up a valuable and regionally new body of information relating wind and water movements. This would amplify the content of the excellent paper of Lawford and Veley: "The Relationship between Local Wind and Current in Coastal Waters of the British Isles" (N.I.O. Internal Report, July 1955).

The aim would everywhere be of course to work out such good interrelationships between winds and water movements that the latter would become deducible from the former well enough for application to questions of pollutant dispersal. Dr. Romanovsky and many others have dealt in an illuminating way with the question of deep bottom currents and their importance if noxious materials be confined to deeps in the oceans. We have ourselves provided simple ways of making observations of deep bed current (one without depth limit) which are easy to use and would avail to compile information on the bottom water movements in the deepest parts of the North Sea.

I leave it to my Lowestoft friends to talk of work done with bottom-drifting indicators and plastic envelopes, and pass on now to consider one other device which I think could very well be of real use to those who have to study pollutant dispersals. My Lowestoft friends will probably have much of absorbing interest to tell you about the results from the great experiments made with Rhodamine- $B$ in the North Sea, and I would only add a few words regarding some singularly successful experiments carried out recently in South African waters which have a close relevance to our present interests. Using floats with attached dye bags, the investigators were able to take very illuminating photographs from aircraft. These showed the positions reached after various time intervals by moving floats having 
a modest aureole of stained water around them, away from an anchored float from which a long dye streak had extended.

If my concern here were with work that has been done rather than with work which I suggest should additionally be done, I would of course review the excellent large-scale detailed work on North Sea currents carried out in recent years by the German Hydrographic Institute.

Returning to my own theme, I would like to speak for some minutes about the use of floats. These have been much used over the years of course in connection with cases of sewage pollution. Where the beaches of watering places have been fouled (sometimes visibly or odorously fouled!) by crude sewage material, there has often been the wish to decide without any doubt whatever which offending outfall could be held accountable, or, if the local Authority were itself to blame, whether the nuisance could be abated or avoided entirely if the discharge into the sea were merely restricted to certain states of the tide.

There are some very obvious problems and limitations attached to the use of ordinary kinds of floats which could go on drifting continuously, and I need not enumerate them to an audience such as this. A dozen or so years ago, because of interest in questions posed regarding beach pollutions from sewage discharges made into the sea, the idea appealed to me of making a certain kind of automatic float. This would start its drift with scant enough freeboard to minimise windage, would travel with the movement of the water for a prescribed time, and would then anchor itself. When it did so it would take on buoyancy enough to avoid being pulled under by a brisk stream, and would exect a mast carrying a flag bearing an identity number.

The automatic float made at that time was not however progressed beyond a single test at sea because its functioning depended upon an explosion. The problem was how to arrange for the dropping of a heavy anchor after the lapse of a clockmeasured interval of time - exactly one hour in the first case. The only way then seen which would be independent of anchor weight and free of variation due to weather, was to have recourse to a minor explosion. Small though this was, the construction was troublesome because the working parts had to be enclosed. The method was abandoned and no details need presentation here.

Because of the increased interest in everything to do with the dispersal of noxious effluents passed into the sea, it was decided to re-design the float so that it could serve to give realistic answers to various problems such as those raised when decisions have to be made regarding the provenance of bathing-beach pollutions (for instance) when these are clearly due to the arrival of sewage effluents. It would be useful to be able to demonstrate beyond doubt what could be the water travel per hour, per two hours etc. etc., away from a sewage outfall at all states of tide irrespective of weather conditions.

A new version of the float recently made and tested at sea goes under the nickname "Pooh-bah float". It costs very little and is simple to make. Its buoyancy is provided by three one-gallon polythene jerricans of negligible cost enclosed in a light wooden frame. When set adrift the float rides in the water with scant freeboard so as to minimise windage, and yet possesses enough buoyancy when it anchors itself 
not be pulled under in a strong stream. If it were so pulled under then there could be no array of anchored floats to be photographed from the air or viewed or surveyed by interested persons - and recoveries would have to await slack water. What is done is to provide the float with expendable ballast (a sack of gravel) which is shed when the anchor drops.

The necessary timed powerful operating force is obtained thus: A bicycle pump filled with water is closed at its valve end by a small brass cock of the kind fitted to toy steam engines. The filled bicycle pump has powerful closure tension applied to it by a stretched "Sandow", i. e. by one of those braidcovered round rubber hook-ended stretchers used to fasten parcels on to bicycle carriers. So long as the cock is closed no water escapes but, once the cock is opened, the pump evacuates with a rush. It is arranged that when it does so the pump handle pulls behind it a small horizontal guillotine contrived from a common office razor blade knife. The little closure cock is fitted with a lever handle which has to maintain its initial closed position against the stretch of a long length of elastic. This it can do initially because the pull of the elastic is countered by a certain string (a length of smooth thin plastic braid) which leads through a leakproof hole in the side of a watertight circular box screwed down on the float top with its rubber-lined removable lid held down by means of another stretched "Sandow". Within the box is a common alarm clock held down tight (face downwards) upon a rubber pad. The alarm-winding handle of this clock has a little brass peg secured into the rear side of one wing of it - horizontally. On to this peg is hooked a small loop which is terminal on the "string" which comes through the side of the box and counters that pull which, if let go, would open the closure cock of the bicycle pump.

Clearly, if the float be set adrift say at 6 o'clock with the alarm set for 10 o'clock then, after four hours of drift, the alarm-winding handle will turn to release the restraint and will let the pump evacuate quickly. When it does so the powerful catapult action draws the guillotine blade through a piece of vinyl tubing. This cuts cleanly (as nothing else tried will do) and both drops the anchor and jettisons the expendable bag of gravel ballast. The anchor line is wound on to a holder contrived from half a fishermens' alloy float from which it can run off freely. Soft line must not be used because it binds. What have served with complete success are both polythene braid and stranded wire cord.

The vinyl tubing is held strained at short length by simply transfixing it by common woodscrews as figured. At the time the vinyl tube is cut the flag mast erects itself. When the anchored float is retrieved it can be stood on end and a handle fixed in the manner shown to wind in the anchor line. In the initial situation the line is held under control on the hemisphere by means of a tie of knitting wool which easily breaks when the anchor drops.

Though it is expected that the float, which is timeable exactly for from one to twelve hours, will be used mostly for tracking water movements in shallow areas, it will serve if so desired where the water is deep. In such case a long length of wire holding the anchor could be hanging free initially with perhaps only some fifty fathoms or so held on the drum. The weight would be taken at the initial stage by connecting the link to be cut with a clamp screwed on to the wire instead of directly to the anchor. 
Also of course, the expendable gravel ballast could "hang deep" initially and there could be, if so wished, a drogue attached to the anchor.

I am sorry that by restricting myself to suggestions for new work with little reference to work already done, I have inevitably subjected you to somewhat of a dull talk. However, I hope that you will see in my various suggestions something realistically directed towards getting that increased knowledge of North Sea currents which is necessary if we are to give the best advice as to where effluent discharges could least-objectionably be made, or noxious material least-offensively dumped.

Perhaps the automatic float may have other uses than those for which I made it, and I might remark that, although I have borne in mind the official definition of "pollution", I have not forgotten the work of K. KaLLE in which he pointed out the beneficent effects of the Thames outflow. Clearly, sewage pollution near at hand may be a very different thing from sewage effects at long distances so to speak.

So far as I know, a kind of pollution looming large in some places has not yet come to the North Sea. This is the passage into the sea of vast volumes of dense brine produced by desalination plants. If come it does, then the location of the discharge will perhaps set problems of extra difficulty.

\section{SUMMARY}

1. Exact knowledge of water circulation in the North Sea is required before we can put advice, concerning the effects of pollutants discharged into its waters, on a sounder basis.

2. A number of steps, which certainly could be performed in praxis, and which would increase our present knowledge of the movements of the North Sea's water, are discussed. 